Florida International University FIU Digital Commons

Department of Epidemiology

Robert Stempel College of Public Health \& Social

Work

$12-20-2011$

\title{
Correlates of Intimate Partner Physical Violence Among Young Reproductive Age Women in Mysore, India
}

Purnima Madhivanan

Department of Epidemiology, Florida International University; Public Health Research Institute of India, pmadhiva@fiu.edu

Karl Krupp

Public Health Research Institute of India; Health Promotion and Disease Prevention, Florida International University, kkrupp@fiu.edu

Arthur Reingold

University of California - Berkeley

Follow this and additional works at: https://digitalcommons.fiu.edu/epidemiology

Part of the Medicine and Health Sciences Commons

\section{Recommended Citation}

Madhivanan, Purnima; Krupp, Karl; and Reingold, Arthur, "Correlates of Intimate Partner Physical Violence Among Young Reproductive Age Women in Mysore, India" (2011). Department of Epidemiology. 22.

https://digitalcommons.fiu.edu/epidemiology/22 


\title{
Correlates of Intimate Partner Physical Violence Among Young Reproductive Age Women in Mysore, India
}

\author{
Purnima Madhivanan, MBBS, MPH, PhD ${ }^{1,2}$, Karl Krupp, MPH $^{2}$, and Arthur Reingold, MD $^{3}$ \\ ${ }^{1}$ Florida International University, Miami, FL, USA \\ ${ }^{2}$ Public Health Research Institute of India, Mysore, India \\ ${ }^{3}$ University of California, Berkeley, Berkeley, CA, USA
}

\begin{abstract}
Few studies have examined intimate partner physical violence (IPPV) in south India. This article examines the frequency and correlates of IPPV among 898 young married women from urban, rural, and periurban areas of Mysore, India. Most (69.2\%) of the participants were Hindus and $28.7 \%$ were Muslims. Overall, 50\% of participants reported some type of IPPV. Factors that were independently associated with IPPV included being younger than 18 years at the time of marriage, contributing some household income, having anal sex, reporting sexual violence, and having a sex partner who drinks alcohol and smokes cigarettes. Women with skilled occupation were at reduced odds of experiencing IPPV compared with women who did not work. These findings suggest that IPPV is highly prevalent in this setting and that additional interventions are needed to reduce morbidity particularly among young women. These data also suggest that more studies are needed among men who perpetrate IPPV in south India.
\end{abstract}

\section{Keywords}

income; India; intimate partner; violence; women

\section{Introduction}

Intimate partner physical violence (IPPV) is a pervasive public health problem affecting both developed and developing countries. ${ }^{1}$ More than 50 population-based surveys from 46 countries report that from $10 \%$ to $69 \%$ of women report being hit or otherwise physically harmed by their intimate partner at some point in their lives. ${ }^{2}$ As many as 52\% reported physical violence in the previous 12 months, and up to $45 \%$ say it occurred in their current relationship. ${ }^{3}$ Not only is IPPV highly prevalent, it also has substantial impact on health. In studies from across the world, physical violence carried out by intimate partners has been linked to serious physical injuries, homicides, unwanted pregnancies, miscarriages, induced abortions, and vulnerability to HIV and other sexually transmitted infections. ${ }^{4-6}$

A number of risk factors have been associated with IPPV. Women reporting physical assault by an intimate partner are usually younger in age, ${ }^{7}$ lower in socioeconomic status, ${ }^{8}$ lower in

\section{(C) 2011 APJPH}

Corresponding Author: Purnima Madhivanan, Department of Epidemiology, Robert Stempel College of Public Health and Social Work, Florida International University, 11200 SW 8 Street, HLS 390W2, Miami, FL 33199, USA, purnima.madhivanan@ fiu.edu.

Declaration of Conflicting Interests

The author(s) declared no potential conflicts of interest with respect to the authorship and/or publication of this article. 
educational attainment,, 79 and lack a remunerated occupation. ${ }^{10}$ Partner characteristics most predictive of IPPV among women includes lower educational attainment, ${ }^{11,12}$ alcohol abuse, ${ }^{9,13}$ multiple partners, ${ }^{13}$ illegal drug use,,${ }^{8,12}$ and irregular or intermittent employment. ${ }^{14}$ Studies have also found that IPPV is frequently found concurrently with sexual violence. ${ }^{15}$ Findings are mixed about whether one type of violence precedes or predicts the other. Mohammadkhani et al, ${ }^{16}$ for instance, found that the experience of physical or psychological violence increased the likelihood of sexual violence victimization. Trickett et al, ${ }^{17}$ on the other hand, found that sexual abuse predicted later victimization with physical or further sexual violence. Whatever the case, women experiencing one form of victimization appear to be at much greater risk for experiencing another form. White and Smith, ${ }^{18}$ in a study of dating violence in the United States, found that women who experienced one form of victimization were 4.5 times more likely to also experience the other.

Only a small number of studies have examined both the prevalence and risk factors for IPPV among women in India. During 1997-1999, the International Clinical Epidemiologists Network (INCLEN) in collaboration with the International Center for Research on Women (ICRW) conducted a household survey in 7 Indian cities. They found lifetime IPPV ranging from $12 \%$ in non-slum urban areas of Delhi to $65 \%$ in inner-city slums in Nagpur.

Approximately $26 \%$ of women had experienced either physical or sexual violence in the past 12 months. ${ }^{19}$ Risk factors for physical violence included alcohol use by spouse, dowry harassment where a woman is bothered or harassed for dowry by her fiance's family or relatives, harsh physical punishment as a child, and witnessing family violence. ${ }^{19,20} \mathrm{Babu}$ and $\mathrm{Kar}^{21}$ conducted a population-based study in eastern India and found an overall lifetime prevalence of IPPV of $16 \%$. Predictors of physical violence included age, rural/urban residence, religion, caste, and household income. ${ }^{21}$ Rocca et al, ${ }^{22}$ in a study of 744 married women in low-income communities in Bangalore, found more than half (56\%) of study participants had reported having ever experienced physical violence; and $27 \%$ reported violence in the prior 6 months. Women in "love marriages," those where the family did not select a spouse, and those participating in activities outside the home were at higher risk for domestic violence. ${ }^{22}$ Dalal and Lindqvist, ${ }^{23}$ in a study using data from the Government of India National Family Health Survey 3, 2005-2006, found reported lifetime prevalence of emotional violence of $14 \%$, less severe physical violence of $31 \%$, severe physical violence of $10 \%$, and sexual violence of $8 \%$.

Unfortunately, previous studies of IPPV in India have been difficult to generalize to different populations within the country and across the world. Existing studies have used a variety of indicators and instruments for measuring intimate partner violence making interand cross-country comparisons difficult. The most comprehensive study, a household survey carried out in 2000 by INCLEN,${ }^{19}$ predated efforts by the World Health Organization (WHO) to standardize definitions and survey questions for IPPV in $2003 .^{2}$ The study by Babu and $\mathrm{Kar},{ }^{24}$ although robust, also used a custom instrument that complicated comparisons with other populations within and outside India. Additionally, India is a populous and heterogeneous country with a variety of different populations. The few studies that have been done on IPPV, although informative, have only described a small crosssection of women in this vast country. Current studies have mainly been predominantly among urban populations in India's largest cities. Whether women living in urban and periurban areas of the country face the same levels of violence is still a very open question.

This study investigated the prevalence of and risk factors for IPPV using standardized measures developed by the WHO for the WHO Multi-Country Study on Women's Health and Domestic Violence. ${ }^{2}$ The research explores the prevalence of intimate partner violence 
reported by young reproductive age women living in urban, periurban, and rural areas of Mysore district in the south Indian state of Karnataka.

\section{Methods}

\section{Study Population and Study Design}

Cross-sectional analyses of baseline findings were done of a prospective cohort study of young married women to investigate the prevalence and correlates of IPPV. The prospective cohort study was designed to examine the relationship of abnormal vaginal flora and acquisition of herpes simplex virus type 2 infection among young reproductive age women in Mysore, India. Study participants were recruited between November 2005 and March 2006. The recruitment process is described elsewhere. ${ }^{25}$ In brief, women were recruited through health education programs offered in the rural and periurban communities around Mysore city in south India. At the end of the health education program, women were invited to participate in the study and get screened for reproductive tract infections. Interested participants were given contact details and asked to visit the study sites at either CSI Holdsworth Memorial Hospital or Chitra's Hospital. At baseline, and at 3- and 6-month visits, participants underwent an interviewer-administered questionnaire and a physical examination, during which biologic specimens, including vaginal, high cervical swabs, and venous blood, were collected for screening of reproductive tract infections. For inclusion, participants had to be between 15 and 30 years old, sexually active, willing to undergo a pelvic examination, and planning to stay in the area for 6 months. Data were collected from all eligible participants who had undergone informed consent process and given written informed consent. The study was approved by the Committee for Protection of Human Subjects at the University of California, Berkeley, and Asha Kirana Institutional Review Board, Mysore, in compliance with federal regulations on protection of human subjects.

\section{Interview}

Eligible consenting women were assigned a study identification number. All subsequent documents were coded with the study identification number and no personal identifiers. Participants underwent a structured 40-minute interview in the local language of Kannada by trained interviewers.

\section{Study Questionnaire}

Information was collected in the following domains

Sociodemographic variables: These included age, education, religion, marital status, monthly household income, and occupation.

Violence variables: 12 items on sexual violence and 12 on physical violence. Sexual violence items were asked before physical violence items.

Sexual risk variables: Unprotected vaginal, oral, and anal sex in prior 3 months and lifetime; number of sex partners in past 3 months and lifetime; and having sex while partner was under the influence of alcohol.

Local multilingual staff were hired and trained on all aspects of the study. A manual of operations with written protocols were developed on data collection, including recruitment, obtaining consent, orienting participants, specimen collection, and follow-up procedures. Interviewers were trained to administer the questionnaire in a standardized nonjudgmental fashion. One of the guiding principles of training was the assurance of confidentiality of any information divulged through contact with participants. The WHO ethical and safety recommendations for research on domestic violence against women were used as a guide. ${ }^{26}$ 


\section{Measures}

IPPV was measured with 12 items that were used by the WHO multi-country domestic violence study. ${ }^{15}$ Each IPPV item had 4 responses: 0 (never or 0 times); 1 (rarely or 1-2 times a year); 2 (sometimes or less than once a month); 3 (frequently or at least once a month). Responses were collapsed into 2 categories with " 0 " describing not experiencing violence and " 1 " experiencing violence. A composite variable was developed for IPPV that aggregated all the 12 items describing IPPV in the prior 12 months. Similarly, sexual violence was measured with 12 items and each item also had 4 responses as with IPPV. A composite sexual violence variable was developed that measured whether a women had experienced any of the 12 items describing sexual violence in the past 12 months. See text box below for measures used to document physical and sexual violence by intimate partner.

Measures used in the study to document physical and sexual violence by an intimate partner in the past 12 months and during pregnancy:

Sexual violence by an intimate partner

- Forced to have sex when she did not want to because she was afraid what he might do if she refused

- Forced to have sex when she was not willing

- Physically forced to do something sexual that was degrading or humiliating

- Used force (such as hitting, holding her down, or using a weapon) to make her have sex

- Forced to have sex when her judgment was impaired (drugged, medicated, or asleep)

- Forced to have sex when/where other people may hear/see

- Criticize or humiliate her about sex

Physical violence by an intimate partner

- Slapped, hit, kicked, beat, pushed, or shoved her

- Pulled hair or dragged her by her hair

- Smothered, choked, or attempted to or actually strangled her

- Thrown something at her or burned her with hot object or water

- Put dangerous substance on her to hurt her (acid/kerosene)

- Used a weapon to hurt her physically

\section{Statistical Analysis}

Data were entered in an Access database and analyzed in Stata 10.0 (Stata Corporation, College Station, TX). Univariate associations of baseline characteristics for IPPV were made using Pearson $\chi^{2}$ test of Fischer exact methods. Variables with $P$ values less than .05 were considered for inclusion in unadjusted and adjusted logistic regression models with test of significance being 2 -tailed $(P<.05)$. Confidence intervals were calculated at the $95 \%$ level.

The unadjusted logistic regression models included preselected variables to examine their association with IPPV. The models included sociodemographic characteristics such as education, religion, occupation, contribution to household income, age at marriage; sexual risk variables such as oral and anal sex in lifetime, having sex while partner was under the influence of alcohol, and having experienced sexual violence; and partner characteristics 
included education, occupation, other sex partners, alcohol and cigarette use. Variables with $P$ values less than .05 were considered for inclusion in a multivariable logistic regression model. Tests of significance were 2 -tailed $(P<.05)$. All confidence intervals were calculated at the $95 \%$ level.

\section{Results}

A total of 2131 women were screened for the study out of which 1193 were eligible, 996 (83\%) agreed to participate, and 898 completed the baseline questionnaire.

\section{Social and Demographic Characteristics}

The mean age of participants was 25.8 years (range: 16-30 years). About $74 \%$ reported their sole occupation as "housewife." About $20 \%$ reported working as unskilled agricultural laborers or rolling incense sticks or beedis, and $6 \%$ had other occupations. More than a third of participants reported not contributing anything to the household income (see Table 1).

\section{Sexual Risk Behaviors}

In total, 55 women $(6.1 \%)$ reported ever having anal sex, of whom 41 reported having anal sex in the past 3 months. A total of 40 women (4.5\%) reported ever having oral sex, of whom 34 reported having it in the past 3 months. About 360 women (40.1\%) reported having sex while their partner was under the influence of alcohol, and $98 \%$ of those sex acts were unprotected.

\section{Partner Characteristics}

As shown in Table 2, a third of the participant's partners were illiterate, $45 \%$ were unskilled workers, and $44 \%$ skilled; $11 \%$ of the participant's partners were drivers. In India, drivers in particular have been found to have highly risky lifestyle, which places them at increased risk for HIV, sexually transmitted infections, and marital problems, including multiple sex partners and violence. Hence we disaggregated "drivers" as an occupational category. About $8 \%$ women reported that their partners had other sex partners. In addition, $43.5 \%$ and $48.4 \%$ of participants said their partners drank alcohol and smoked cigarettes, respectively.

\section{Prevalence and Correlated of Physical Violence}

Overall, 50\% of participants reported some type of IPPV, and 5.7\% said they experienced physical violence during their pregnancy. Table 3 describes the frequency and types of physical violence reported for the previous 12 months.

Women experiencing IPPV had less education, lower job skill levels, lived longer with their partners, contributed some household income, and were younger than 18 years at the time of marriage. They were also more likely to report anal sex, sex with a partner under the influence of alcohol, and sexual violence. Women who experienced IPPV were also more likely to have partners with less than 7 years of education who used alcohol and cigarettes and had other sex partners.

Unadjusted analyses showed that women with more than 7 years of education had 0.65 times the odds of experiencing IPPV as compared to women with no education (95\% confidence interval $[\mathrm{CI}]=0.47-0.89$ ). . Participants reporting skilled jobs had 0.54 odds of experiencing IPPV as compared to women who were unskilled/housewives $(95 \% \mathrm{CI}=0.30-0.98)$. Women who contributed some household income were at 2.39 (95\% CI $=1.64-3.48)$ times the odds of experiencing IPPV compared with women who contributed no income. Women younger than 18 years at the time of marriage were at $1.70(95 \% \mathrm{CI}=1.25-2.32)$ times the odds of experiencing IPPV as compared with women older than 18 years at marriage. 
Women who reported anal sex had 2.35 increased odds of also reporting IPPV as compared with those women who did not $(95 \% \mathrm{CI}=1.30-4.23)$. Women saying their partners had other sex partners were at 2.11 the odds of reporting IPPV (95\% CI $=1.26-3.55)$. Similarly, women reporting that their partner drank alcohol were at 2.49 (95\% CI $=1.90-3.27)$ times the odds of experiencing IPPV compared with those who did not. In addition, women whose partners smoked had $1.82(95 \% \mathrm{CI}=1.40-2.37)$ times the odds of IPPV as compared with women with nonsmoking partners. Finally, women who reported intimate partner sexual violence were at 5.68 increased odds of also experiencing IPPV as compared with women who did not report sexual violence $(95 \% \mathrm{CI}=4.18-7.70$; Table 4$)$.

Factors found significant in the unadjusted analysis were included in the multivariable logistic regression model. Those that remained independently associated with an increased relative odds of IPPV included being younger than 18 years at the time of marriage, contributing some of the household income, having anal sex, having a partner who drinks alcohol and smokes cigarettes, and reporting sexual violence. Finally, woman with a skilled occupation also were at reduced odds of experiencing IPPV.

\section{Discussion}

In this study of 898 young married women from rural and periurban areas around Mysore, about half reported experiencing IPPV in the previous 12 months and 6\% reported IPPV during pregnancy. While these data are roughly comparable to findings from other parts of the world, ${ }^{2}$ they appear higher than other studies from India. For instance, in the largest, multisite study conducted by INCLEN and ICRW, only $26 \%$ of women reported any type of intimate partner violence in the previous year. ${ }^{19}$ Rocca et al, ${ }^{22}$ in a study of south Indian urban women, reported that $27 \%$ of study participants had experienced physical violence in the previous 6 months.

These variations in IPPV prevalence found across different studies point to some of the difficulties in collecting data on interpersonal partner violence in developing countries. First, it appears important that researchers adopt a standardized set of measures such as those developed by the $\mathrm{WHO}^{15}$ to make comparability easier across different populations. As the literature also shows, estimating prevalence of IPPV is highly susceptible to

underreporting. ${ }^{27}$ Most incidents of IPPV are revealed and the exceptions are typically only reported to friends, neighbors, religious institutions, or community groups. In this case, our study hired interviewers directly from the communities where the survey was carried out, and we believe this increased the willingness of women to share even highly sensitive information on IPPV. Finally, India is a highly heterogeneous country. Differences in cultural and social norms that condone violence may be reflected both in the willingness of victims to identify themselves and in the levels of violence found in households.

Univariate analyses suggest that a woman's status in the household may play an important role in whether she experiences IPPV. Educational attainment appeared protective. Women with $>7$ years of schooling experienced the lowest levels of IPPV. Similarly, women who said that they had skilled occupations were less likely to experience IPPV. Interestingly, women who contributed some household income were at significantly higher odds of being the victim of violence. This finding is consistent with research from India and other developing countries. ${ }^{28,29}$ On the other hand, studies have found a nuanced relationship between a woman's contribution to household income and experience of IPPV. For instance, female employment typically functions as a protective factor only when a partner is also employed; if an employed woman is partnered with an unemployed or underemployed spouse, her risk of violence increases. It is likely that a woman's contribution of income to a 
household interacts with risk for IPPV in highly complex ways and appears to be contextual. This area is deserving of additional research.

Women who were married at $<18$ years and who reported anal sex were also at significantly increased odds of violence. Partner characteristics played a major role in women's odds for experiencing IPPV. ${ }^{8,9,12-14}$ Having a partner with other sex partners, who drinks alcohol, or smokes cigarettes significantly increased a woman's odds for physical violence. Finally, perhaps not surprisingly, women who reported sexual violence by an intimate partner were also at increased risk for IPPV. All these findings are consistent with the literature both in India and worldwide.

In a multivariable logistic regression model, only having a skilled occupation lowered the relative odds of experiencing IPPV. Similar to unadjusted analysis, being younger than 18 years at marriage, contributing some but not all of the household income, and reporting sexual violence increased the relative odds of IPPV. Similarly, women with partners who drank alcohol or smoked cigarettes had higher relative odds of IPPV after adjusting for other confounders.

The findings of this study suggest that interventions aimed at increasing women's job skills may provide some protection against IPPV. We hypothesize that such training may increase a woman's social networks and improve her status within the family. On the other hand, there is a risk that focusing primarily on providing opportunities for women to contribute some income to the household may actually put some at increased risk for physical violence. We suspect that partial contributions may upset the power dynamic in marital relationships without providing sufficient leverage to negotiate physical safety within the home. Since this study was cross-sectional in design, we were unable to determine if this relationship changed over time. It is possible that increasing a wife's household contribution may exacerbate the risk of violence over the short term but reduce IPPV over time. There is a need for longitudinal studies, which can shed more light on this relationship in India.

As with other studies, ${ }^{8,9,12-14}$ partner characteristics are important correlates of IPPV in India. There is an extensive literature in which use and abuse of alcohol has been identified as a major risk factor for perpetration of physical violence. Other risky behavior such as cigarette smoking has also been associated with IPPV. Additionally, women reporting sexual abuse by their partners were also at increased odds for physical abuse. Although all these correlates have been well discussed, it is worthwhile to point out that there is a compelling need for additional interventions that involve the partners of women experiencing violence.

The results of the study suggest that IPPV is widespread in south India and presents a large public health challenge. Research from across the world suggests that improving the state of the country's women will be critical to development goals for the country. It is clear that IPPV cannot be separated from the overall development of women. On the other hand, ensuring higher levels of education and job skills is clearly only part of the solution. Any effective strategy must also address male partners and the nuanced interaction of gendered social roles with IPPV in this highly traditional society.

Our study has several limitations. There could be recall and information bias as sexual histories were self-reported and retrospective. It is possible that women underreported sexual violence and sexual risk behaviors owing to social desirability bias. Participants also were not knowledgeable about their partners so this may have led to misclassification. Because this misclassification would be nondifferential, the association would lead to a null relationship. As this is a cross-sectional analysis of baseline data of a cohort study, it is not possible to establish causal relationships between the factors examined and IPPV. In 
particular, the temporal relationship between physical violence and sexual violence could not be assessed given the cross-sectional nature of the data. Finally, because the study did not use a random sample, findings may not be generalizable to other populations.

Despite the limitations, this study contributes to the sparse literature on IPPV in south India. Our study also has several strengths, which include a large sample size, highly trained interviewers hired from the community who were able to elicit very sensitive personal information, and standardized measures for violence that were developed for the WHO multi-country domestic violence study, making data more comparable to other studies.

\section{Conclusion}

The findings suggest that IPPV is highly prevalent in this setting and that additional interventions are needed. At the same time, the data also suggest that some caution is warranted with regard to income generation programs aimed at reducing IPPV. Additionally, the findings support the need to better understand the interaction of gendered social roles on IPPV within families.

\section{Acknowledgments}

For their generous assistance on this project, the authors would like to thank the all the nongovernmental organizations who assisted with outreach programs and women in the study for their participation. Special thanks to Dr Chitra Karat and Dr Varalakshmi Chandrasekaran who were supervising data collection and to Fazila Begum, Prabhavathy, Shaila S, Selvi, Rani Chinnappa, and Satyanarayana for assisting with data collection on the project.

\section{Funding}

The author(s) disclosed receipt of the following financial support for the research, authorship, and/or publication of this article:

This study was supported by the National Institute of Health Fogarty AIDS International Training and Research Program (Grant 1-D43-TW00003-16).

\section{References}

1. Heise, L.; Ellsberg, M.; Gottemoeller, M. Ending Violence Against Women. 2003. Population Reports, Series L (11)

2. World Health Organization. WHO Multi-Country Study on Women's Health and Domestic Violence Against Women. Geneva, Switzerland: World Health Organization; 2006. http:// www.who.int/gender/violence/who_multicountry_study/en/. [Accessed September 29, 2011]

3. Population Information Program at the Johns Hopkins School of Public Health. Population report: ending violence against women. Issues in the World. 1999 Series L(11).

4. Silverman JG, Gupta J, Decker MR, Kapur N, Raj A. Intimate partner violence and unwanted pregnancy, miscarriage, induced abortion, and stillbirth among a national sample of Bangladeshi women. BJOG. 2007; 114:1246-1252. [PubMed: 17877676]

5. Gilbert L. Urban violence and health-South Africa 1995. Soc Sci Med. 1996; 43:873-886. [PubMed: 8870151]

6. Decker MR, Seage GR 3rd, Hemenway D, et al. Intimate partner violence functions as both a risk marker and risk factor for women's HIV infection: findings from Indian husband-wife dyads. J Acquir Immune Defic Syndr. 2009; 51:593-600. [PubMed: 19421070]

7. Salari Z, Nakhaee N. Identifying types of domestic violence and its associated risk factors in a pregnant population in Kerman hospitals, Iran Republic. Asia Pac J Public Health. 2008; 20:49-55. [PubMed: 19124298]

8. Rivera-Rivera L, Lazcano-Ponce E, Salmeron-Castro J, Salazar-Martinez E, Castro R, HernandezAvila M. Prevalence and determinants of male partner violence against Mexican women: a population-based study. Salud Publica Mex. 2004; 46:113-122. [PubMed: 15176573] 
9. Jewkes R, Levin J, Penn-Kekana L. Risk factors for domestic violence: findings from a South African cross-sectional study. Soc Sci Med. 2002; 55:1603-1617. [PubMed: 12297246]

10. Andersson N, Ho-Foster A, Mitchell S, Scheepers E, Goldstein S. Risk factors for domestic physical violence: national cross-sectional household surveys in eight southern African countries. BMC Womens Health. 2007; 7:11. [PubMed: 17631689]

11. Bang RA, Bang AT, Baitule M, Choudhary Y, Sarmukaddam S, Tale O. High prevalence of gynaecological diseases in rural Indian women. Lancet. 1989; 1(8629):85-88. [PubMed: 2562890]

12. Reichenheim ME, Dias AS, Moraes CL. Co-occurrence of physical violence against partners and their children in health services. Rev Saude Publica. 2006; 40:595-603. [PubMed: 17063236]

13. Ntaganira J, Muula AS, Siziya S, Stoskopf C, Rudatsikira E. Factors associated with intimate partner violence among pregnant rural women in Rwanda. Rural Remote Health. 2009; 9:1153. [PubMed: 19719363]

14. Hassan F, Sadowski LS, Bangdiwala SI, et al. Physical intimate partner violence in Chile, Egypt, India and the Philippines. Inj Control Saf Promot. 2004; 11:111-116. [PubMed: 15370347]

15. Garcia-Moreno C, Jansen HA, Ellsberg M, Heise L, Watts CH. Prevalence of intimate partner violence: findings from the WHO multi-country study on women's health and domestic violence. Lancet. 2006; 368:1260-1269. [PubMed: 17027732]

16. Mohammadkhani P, Forouzan AS, Khooshabi KS, Assari S, Lankarani MM. Are the predictors of sexual violence the same as those of nonsexual violence? A gender analysis. J Sex Med. 2009; 6:2215-2223. [PubMed: 19493281]

17. Trickett PK, Noll Jg, Putnam FW. The impact of sexual abuse on female development: lessons from a multigenerational, longitudinal research study. Dev Psychopathol. 2011; 23:453-476. [PubMed: 23786689]

18. White, JW.; Smith, PH. A longitudinal perspective on physical and sexual intimate partner violence against women. In: Fisher, BS., editor. Violence Against Women and Family Violence: Developments in Research, Practice, and Policy. Washington, DC: National Institute of Justice; 2004.

19. International Clinical Epidemiologists Network, International Center for Research on Women. Domestic Violence in India 3: A Summary Report of a Multi-Site Household Survey. Washington, DC: International Center for Research on Women and the Centre for Development and Population Activities; 2000.

20. Kaur R, Garg S. Domestic violence against women: a qualitative study in a rural community. Asia Pac J Public Health. 2010; 22:242-251. [PubMed: 19703815]

21. Babu BV, Kar SK. Domestic violence against women in eastern India: a population-based study on prevalence and related issues. BMC Public Health. 2009; 9:129. [PubMed: 19426515]

22. Rocca CH, Rathod S, Falle T, Pande RP, Krishnan S. Challenging assumptions about women's empowerment: social and economic resources and domestic violence among young married women in urban south India. Int J Epidemiol. 2009; 38:577-585. [PubMed: 18952621]

23. Dalal KD, Lindqvist K. A national study of the prevalence and correlates of domestic violence among women in India [Published online ahead of print November 30, 2010]. Asia Pac J Public Health.

24. Babu BV, Kar SK. Domestic violence in eastern India: factors associated with victimization and perpetration. Public Health. 2010; 124:136-148. [PubMed: 20223489]

25. Krupp K, Madhivanan P, Karat C, et al. Novel recruitment strategies to increase participation of women in reproductive health research in India. Glob Public Health. 2007; 2:395-403. [PubMed: 19283635]

26. World Health Organization. Putting Women First: Ethical and Safety Recommendations for Research on Domestic Violence Against Women. Geneva, Switzerland: World Health Organization; 2001.

27. International Center for Research on Women. Women-Initiated Community Level Responses to Domestic Violence: Summary Report of Three Studies. Washington, DC: International Center for Research on Women; 2002. 
28. Koenig MA, Ahmed S, Hossain MB, Khorshed Alam Mozumder AB. Women's status and domestic violence in rural Bangladesh: individual- and community-level effects. Demography. 2003; 40:269-288. [PubMed: 12846132]

29. Hindin MJ, Adair LS. Who's at risk? Factors associated with intimate partner violence in the Philippines. Soc Sci Med. 2002; 55:1385-1399. [PubMed: 12231016] 


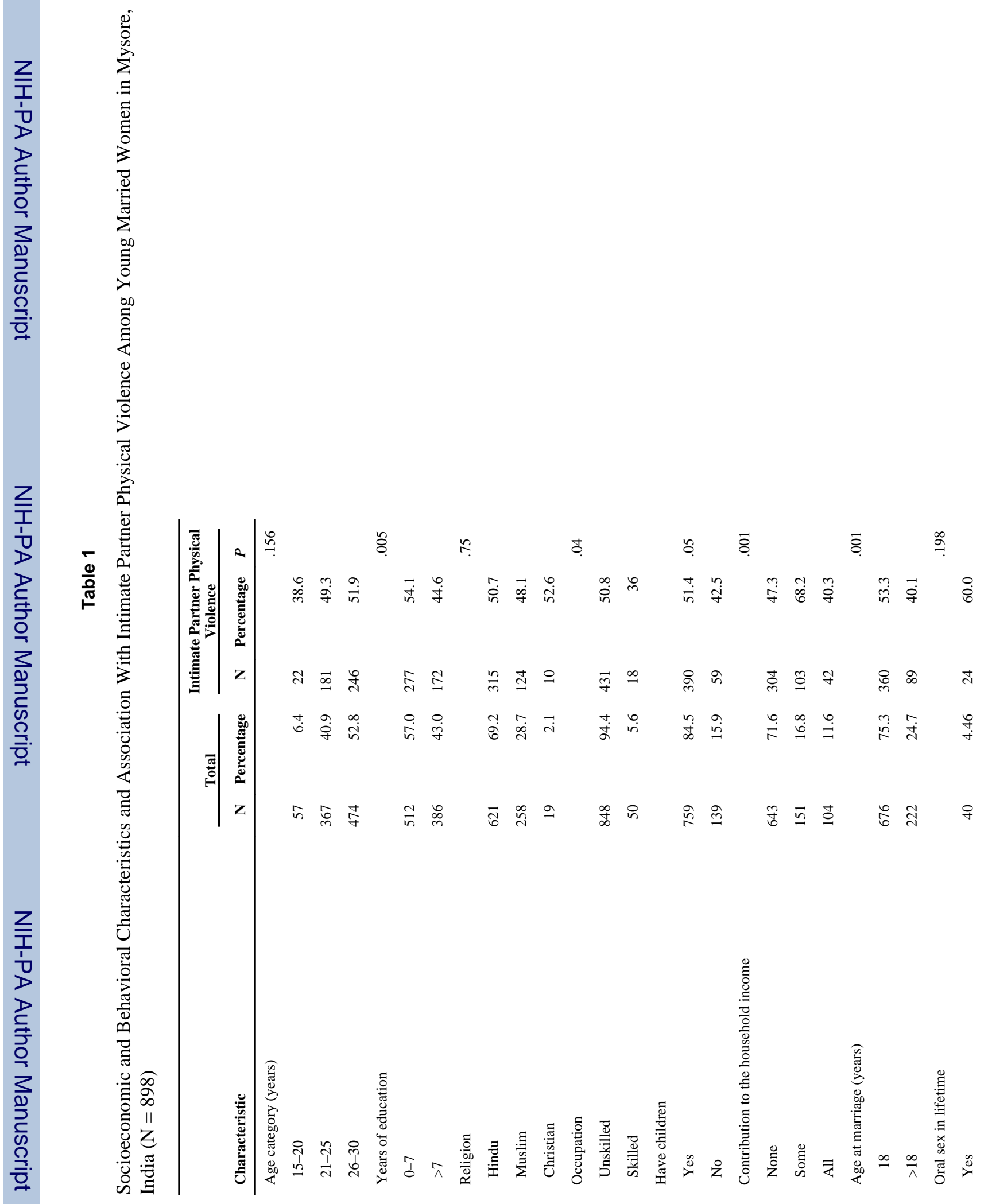




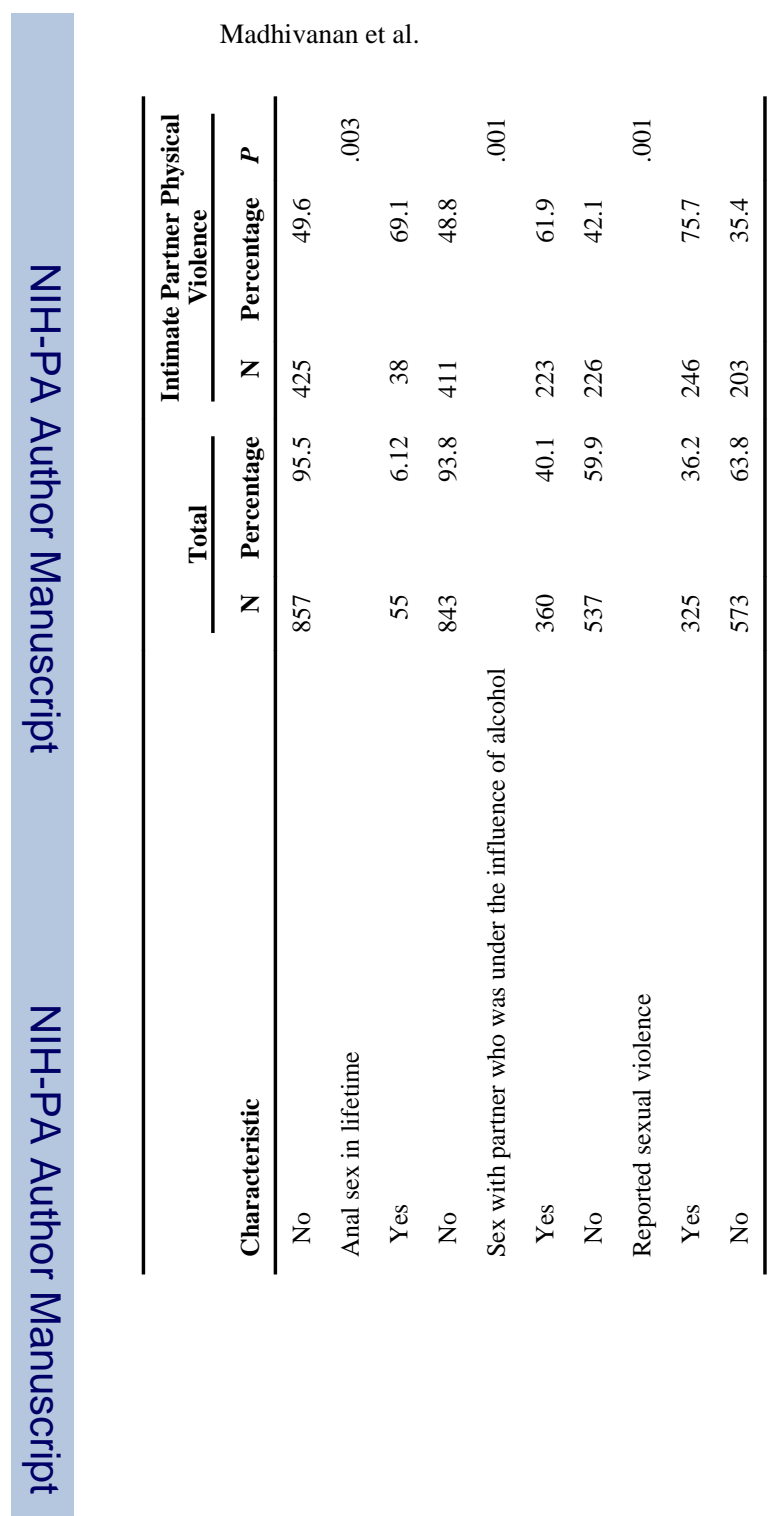

Page 12

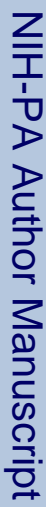

Asia Pac J Public Health. Author manuscript; available in PMC 2013 July 17. 


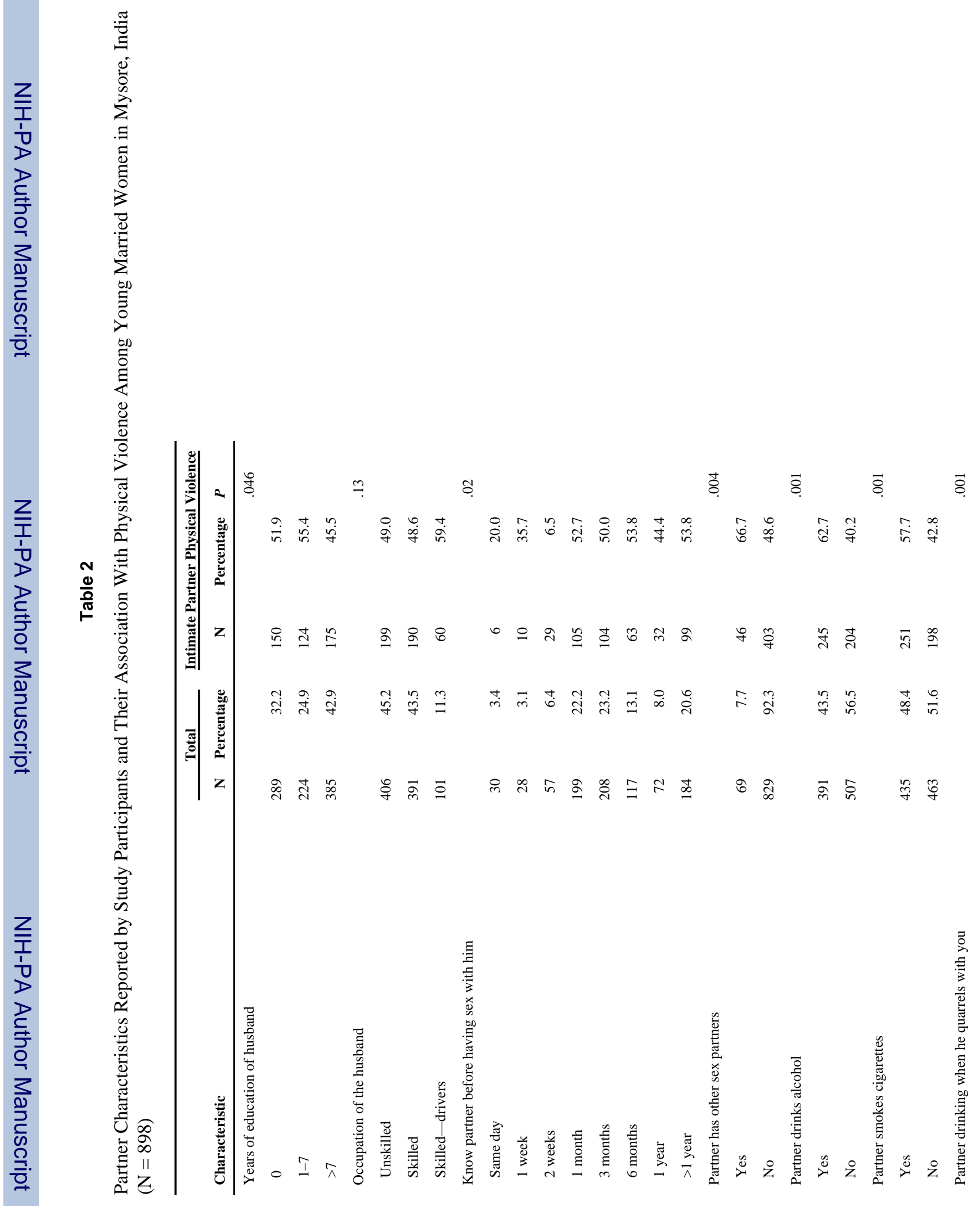




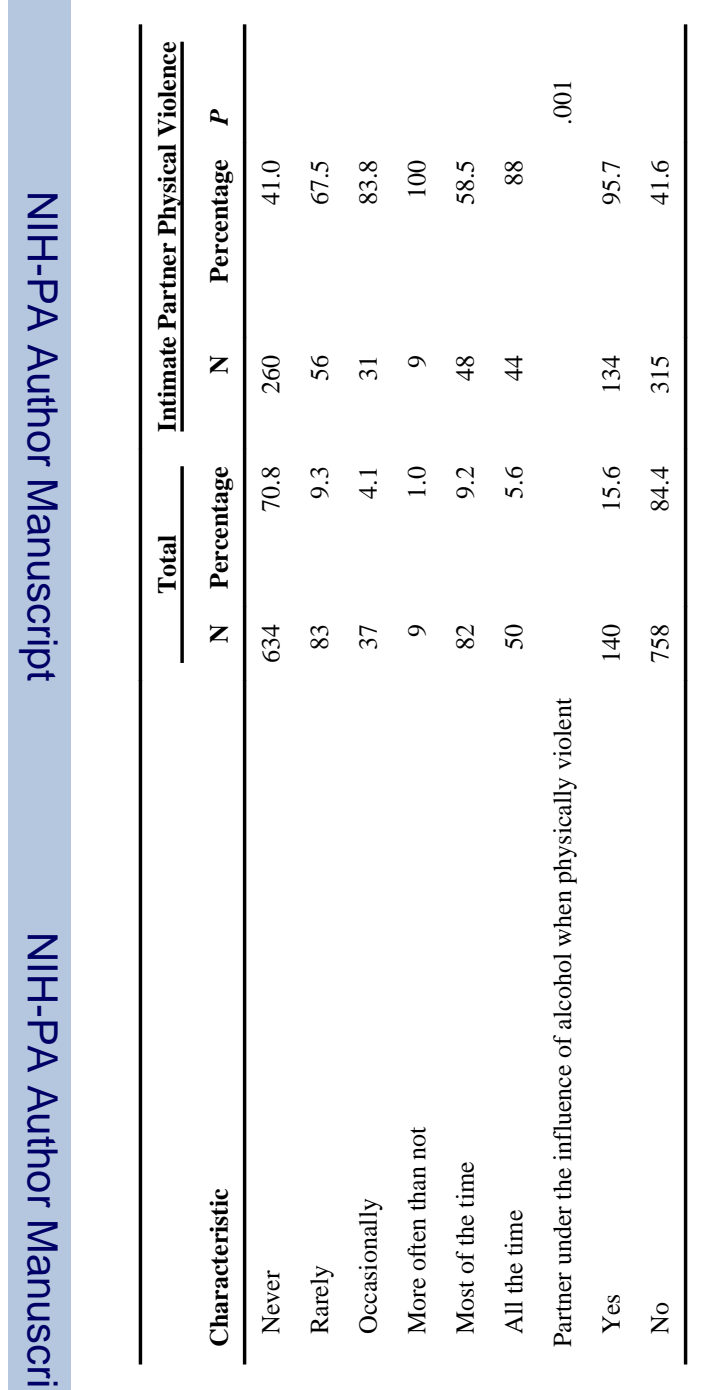




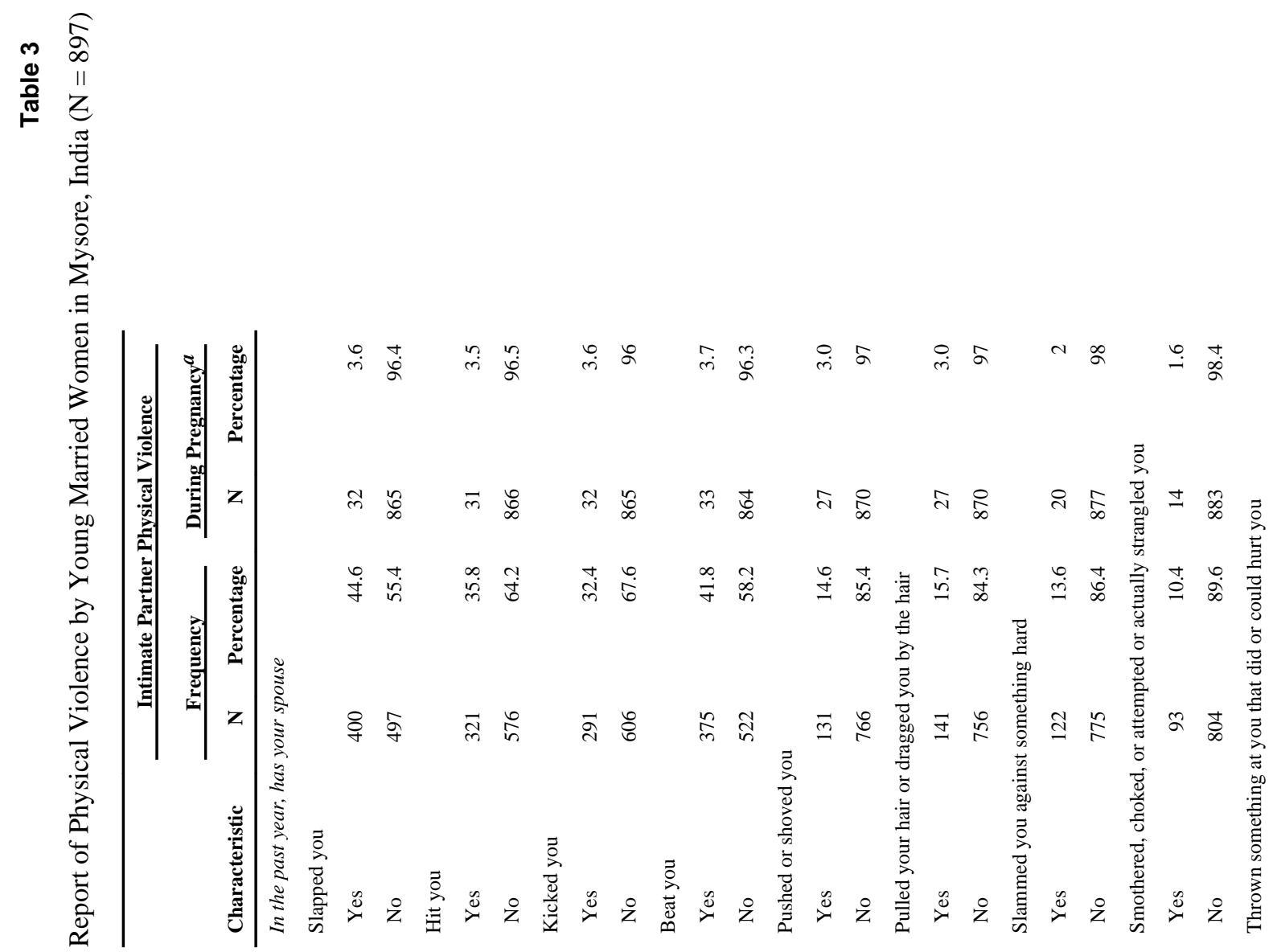




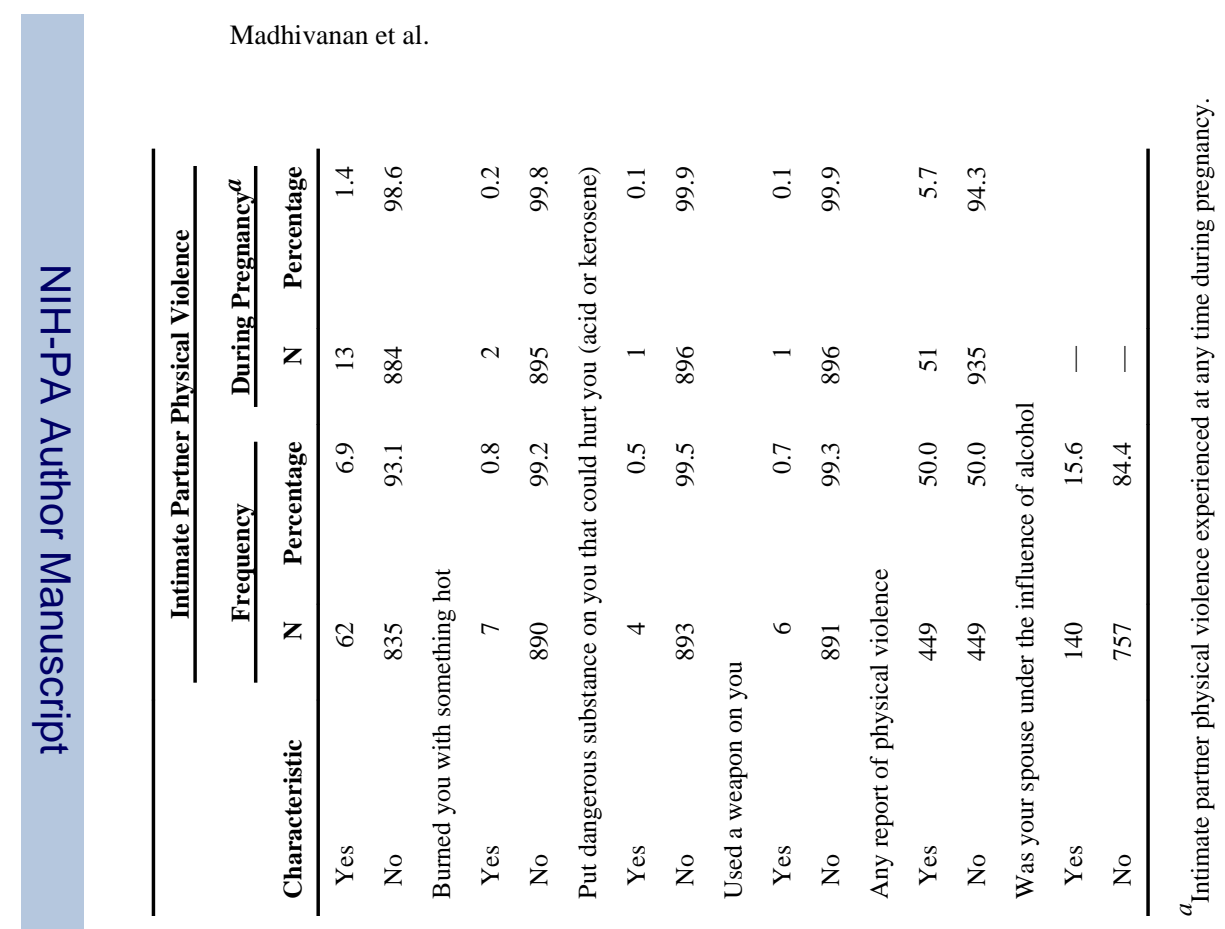

Page 16 


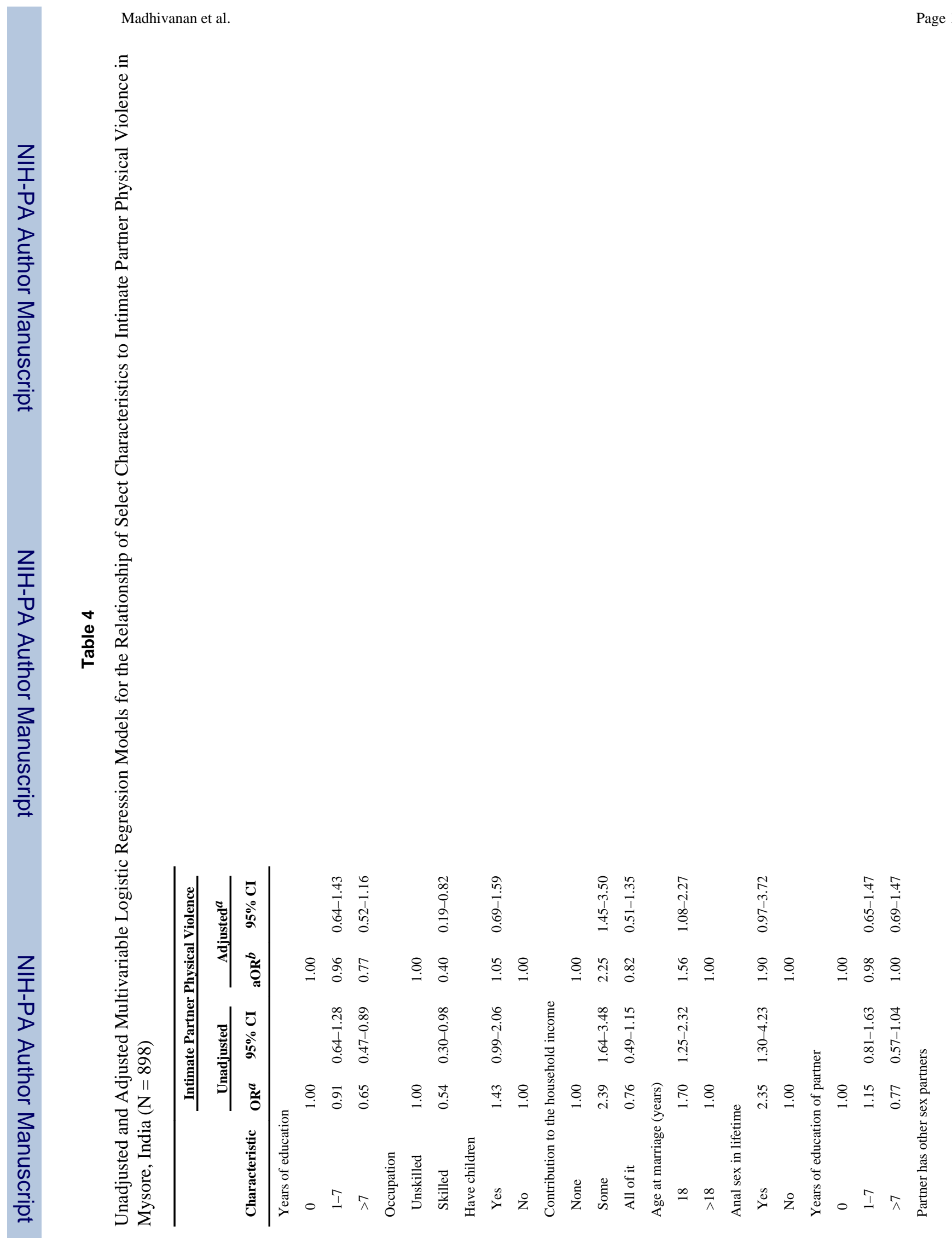




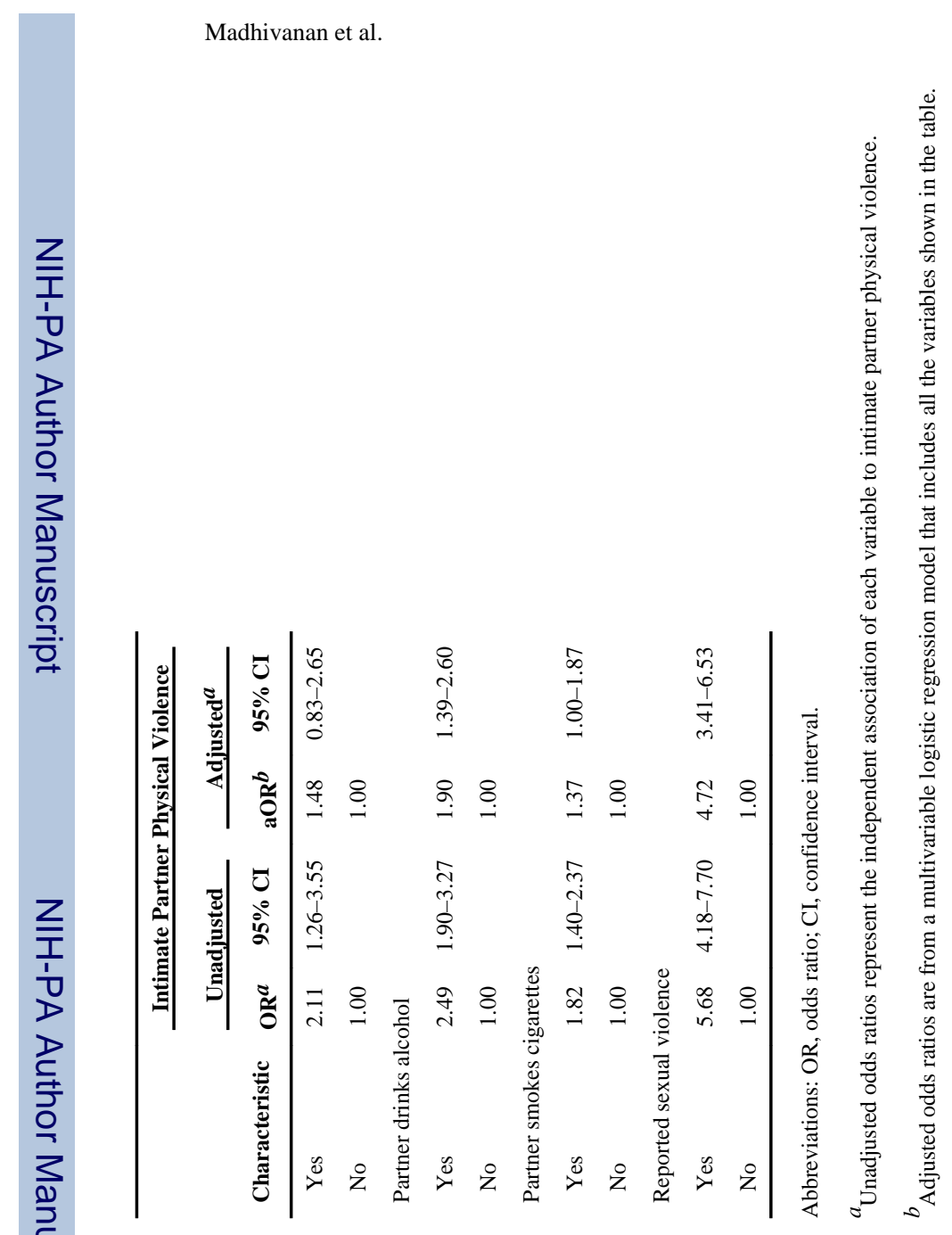

